\title{
THE EFFECT OF DIFFERENT GNSS SOLUTIONS ON THE DIRECT SENSOR ORIENTATION ACCURACY
}

\author{
A. KAYI ${ }^{\mathrm{a}, *}$, H.M. YILMAZ $^{\mathrm{b}}$, A.YILMAZ $^{\mathrm{a}}$ \\ ${ }^{a}$ GCOM, Photogrammetry Department, Cankaya Ankara, Turkey - (altan.yilmaz, abdullah.kayi)@hgk.msb.gov.tr

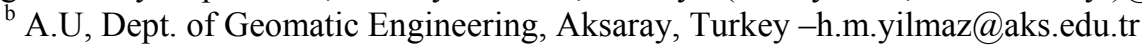

Commission VI, WG VI/4

KEY WORDS: Digital Aerial Camera, GPS\IMU, Direct Sensor Orientation, Direct Georeferencing

\begin{abstract}
:
Direct sensor orientation or direct georeferencing is the solution of exterior orientation parameters using GNSS IMU data without ground control points. Accuracy of the system is based on GNSSIIMU integrated system accuracy. The integrated system containing DGNSS and IMU calculates the approximate exterior orientation parameters during the flight. The exterior orientation accuracy is based on GNSS and IMU accuracy. In this study, the effect of single point, network and PPP GNSS data processes without ground control point on the accuracy of the direct sensor orientation was evaluated. The area of the test region is approximately $1296 \mathrm{~km}^{2}$. 393 images with $30 \mathrm{~cm}$ resolution were used in the study. It was calculated that single point solution horizontal accuracies are (X$\mathrm{Y}) \pm 23-30 \mathrm{~cm}$., vertical accuracy is $(\mathrm{Z}) \pm 40 \mathrm{~cm}$, network solution horizontal accuracies are $(\mathrm{X}-\mathrm{Y}) \pm 24-27 \mathrm{~cm}$, vertical accuracy is $(\mathrm{Z}) \pm 37 \mathrm{~cm}$ and PPP solution horizontal accuracies are $(\mathrm{X}-\mathrm{Y}) \pm 20-28 \mathrm{~cm}$, vertical accuracy is $(\mathrm{Z}) \pm 37 \mathrm{~cm}$.
\end{abstract}

\section{INTRODUCTION}

The exterior orientation parameters are calculated by using bundle block adjustment. At least four GCPs are required to solve the unknowns. Direct sensor orientation or direct georeferencing is the solution of exterior orientation parameters using GNSS $\backslash$ IMU data without ground control points. Accuracy of the system is based on GNSS $I I M U$ integrated system accuracy. The integrated system containing DGNSS and IMU calculates the approximate exterior orientation parameters during the flight. The exterior orientation accuracy is based on GNSS and IMU accuracy (Kiraci, 2008; Ip, 2005). Position accuracy based on GNSS solutions such as single point, Network and PPP. If there is not any ground control point, the GNNS solutions is fatal important for position accuracy. This is why it must be known that which solution is better or effective.

Direct georeferencing is the most cost effective and practical solution for when the availability of ground control points is in question, such as within forest, snow-covered grounds, desert and when emergency response application is required in the case of forest fires, flooding and earthquake. In addition, it can be used in projects that require a single strip or single photo orientation (Ip, 2005).

The method of direct georeferencing is not new and already celebrated 10 years of its successful commercial application and even longer time in academia. (Skaloud, 2007). These are the example of the direct georeferencing;

Direct georeferencing accuracy was investigated in Michael CRAMER (2003) 1:13.000 scaled with 7 images which has 14 $\mu \mathrm{m}$ scan resolution. The horizontal accuracies $\pm 0,26-0,21 \mathrm{~m}$ and vertical accuracy $\pm 0,27$ were met.
In the study, some discrepancies observed between the accuracies. The main reasons for these discrepancies are scale factor, flight attitude, baseline and distance of using master stations. Detail information is given by Jan SKALOUD (2007)

These are other studies of this topic; (Grejner-Brezezinsk 2000), (Jacobsen, 2000), (Mostafa . 2001), (Grewal, 2001), (Cramer and Stallmann, 2002), (Yastıklı, 2003), (Atak and Aksu 2004) and (Jacobsen, 2004).

\section{APPLICATION}

\subsection{Input}

In this study, the effect of different GPS solutions (single point, network and PPP GPS data processes) on the accuracy of the direct sensor orientation without ground control point is evaluated. For this purpose, a flight plan was prepared by WinMp which is the older version of the IGI plan. Flight plan contains 13 east-west and 2 north-south flightlines. The area of the test region is approximately $1296 \mathrm{~km}^{2}$. The flight was accomplished in two days (13-14 June 2012) by UltraCamX large format digital aerial camera. 393 images were taken with $30 \mathrm{~cm}$ ground sample distance by $\% 30$ sidelap and $\% 60$ overlap. Evenly distributed 36 ground control points was measured as check poinst ( Figure 1). Three dimension accuracy of ground control points are approximately $\pm 0.02 \mathrm{~m}$. AeroOffice 5.1 and GrafNav 8.1 were used for GNSSIIMU process and Match-AT 5.5 were used automatic point collection and aerial triangulation. In GNSS $\backslash$ IMU processing 1 second interval GNSS data were used.

\footnotetext{
* Abdullah KAYI.
} 


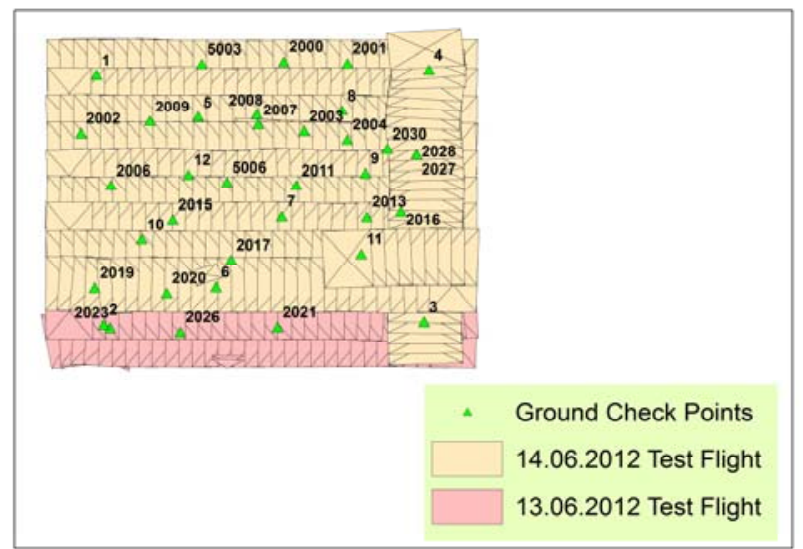

Figure 1. Distribution of check points

\subsection{Single Point Solutions}

For single point solution, there were respectively Ankara, Kirikkale, Yozgat and Sivas base stations alternatives. Ankara base station was the first solution and it stated nearly at the center of the flight area (approximately $5 \mathrm{~km}$ ). Kirikkale base station was used in the second solution. The base station distance is approximately $60 \mathrm{~km}$. In the third solution, Yozgat base station which is $170 \mathrm{~km}$ distance from study area was used. In the last solution, Sivas base station was used. This base station was the farthest station and approximately $360 \mathrm{~km}$ away from the center of the flight area. All master stations shown as Figure 2. After each GPS $\backslash$ IMU process, tie point collection and aerial triangulation were carried out.

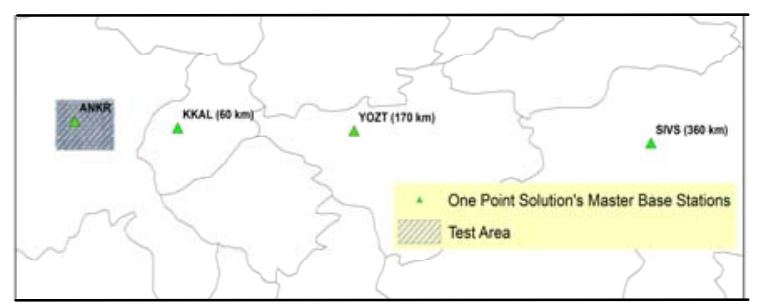

Figure 2. Distribution of single point master stations

\subsection{Network Solutions}

There were four alternative network solutions containing different base configuration and base distances. First network solution has 5 master base stations. Flight area is the center of the network circle and has an approximately $230 \mathrm{~km}$ distance to each base station. Second network solution has 4 stations and has approximately $150 \mathrm{~km}$ distance. Third network solution has 5 base stations and the base distances are approximately $80 \mathrm{~km}$. After third network solution, Ankara base station which is located at the center of the flight area and network containing for other surrounding base stations were added to this network and processed for GPS solution (Figure 3). After GPS process, the tie point collection and aerial triangulation was carried out. It was understood from network_4 solution's combine separation and estimated position accuracy plots, one or more master GNSS stations have defected the dynamic structure of network. The defect was caused by ANKR master base stations data whereas there was no such defeat detected in Network 3 solution combine separation and estimated position accuracy plots (Figure 4 and Figure 5).

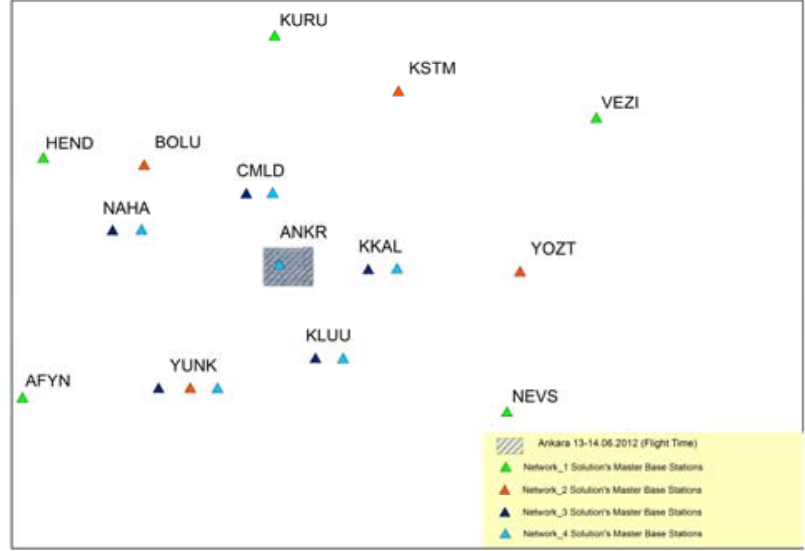

Figure 3. Distribution of networks

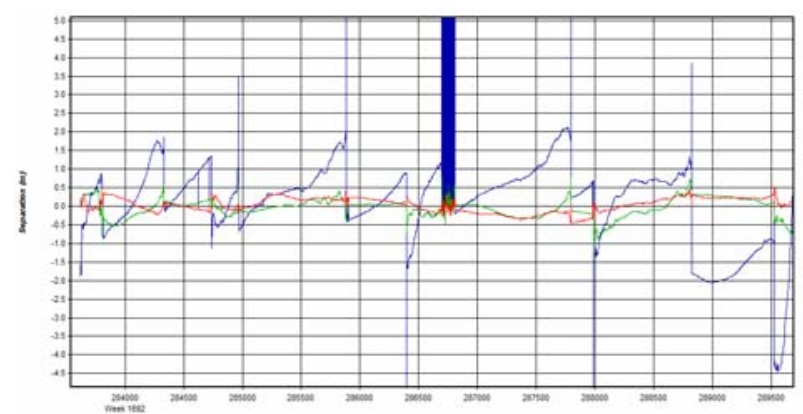

Figure 4. Combine separation of Ankara single point solution

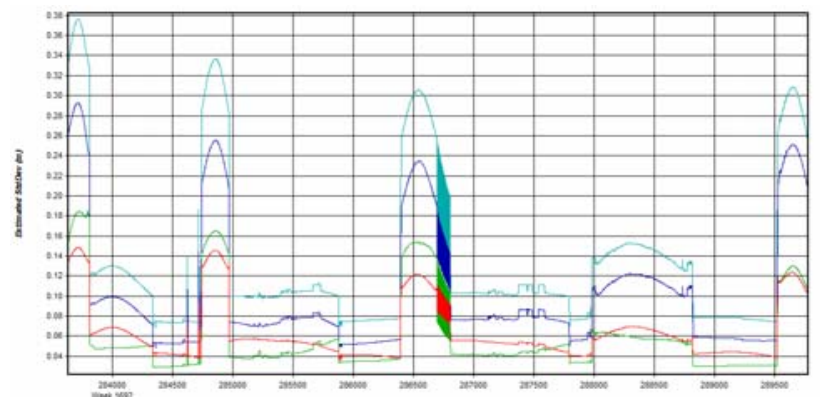

Figure 5. Estimated position accuracy of Ankara single point solution

\subsection{Point Precise Positioning (PPP) Solution}

The ephemeris data consisting satellite orbit and clok errors (igs*.sp3 ve igs*.clk) were downloaded from NASA website.

\subsection{Aerial Triangulation and Results}

For this study, Match-AT version 5.5 was used for automatic point collection and aerial triangulation. Check points were marked on the stereo photo and automatic point collection and aerial triangulation were done in each solution.

In order to see the ideal situation accuracy; Ankara, Kirikkale, Sivas, Network_4 and PPP solution were retriangulatied with using 5 ground control points. All the results obtained were so close to each other and the horizontal accuracies $\pm 0,18-0.19 \mathrm{~m}$ and vertical accuracy $\pm 0,30$ were met. 
For single point solution, there were respectively Ankara, Kirikkale, Yozgat and Sivas base stations alternatives. Ankara base station was the first solution and it was located nearly at the center of the flight area (approximately $5 \mathrm{~km}$ ). After each GPS $\backslash$ IMU process, tie point collection and aerial triangulation were carried out. In this solution RMSE is $\pm 0,206 \mathrm{~m}$ and \pm $0,352 \mathrm{~m}$ in horizontal, and $\pm 1,109 \mathrm{~m}$ in vertical. Kirikkale base station was used in the second solution. The base station distance is approximately $60 \mathrm{~km}$. RMSE is $\pm 0,259 \mathrm{~m}$ and $\pm 0,300 \mathrm{~m}$ in horizontal, and $\pm 0,405 \mathrm{~m}$ in vertical. In the third solution, Yozgat base station which is $170 \mathrm{~km}$ distance from study area was used. RMSE is $\pm 0,233 \mathrm{~m}$ and $\pm 0,305 \mathrm{~m}$ in horizontal, and $\pm 0,395 \mathrm{~m}$ in vertical. In the last solution, Sivas base station was used. This base station was the farthest station and approximately $360 \mathrm{~km}$ away from the center of the flight area. RMSE is \pm 0.436 and $\pm 0.349 \mathrm{~m}$ in horizontal, and $0.587 \mathrm{~m}$ in vertical.

Then, network solution was tested. There were four alternative network solutions containing different base configuration and base distances. First network solution has 5 master base stations. Flight area is the center of the network circle and has an approximately $230 \mathrm{~km}$ distance to each base station. After GPS process, the tie point collection and aerial triangulation was carried out. RMSE is $\pm 0.225 \mathrm{~m}$ and $\pm 0.309 \mathrm{~m}$ in horizontal, and $\pm 0.475 \mathrm{~m}$ in vertical. Second network solution has 4 stations and has approximately $150 \mathrm{~km}$ distance. RMSE is $\pm 0.224 \mathrm{~m}$ and $\pm 0.310 \mathrm{~m}$ in horizontal, and $\pm 0.502 \mathrm{~m}$ in vertical. Third network solution has 5 base stations and the base distances are approximately $80 \mathrm{~km}$. RMSE is $\pm 0.249 \mathrm{~m}$ and \pm $0.270 \mathrm{~m}$ in horizontal, and $\pm 0.379 \mathrm{~m}$ in vertical. After third network solution, Ankara base station which is located at the center of the flight area and network containing for other surrounding base stations were added to this network and processed for GPS solution. RMSE is $\pm 0.214-0.306 \mathrm{~m}$ in horizontal, and $\pm 0.369 \mathrm{~m}$ in vertical. Finally PPP solution was tried and the horizontal RMSE $(\mathrm{X}-\mathrm{Y}) \pm 0.206-0.286 \mathrm{~m}$ and vertical RMSE $(Z) \pm 0.449$ m were met.

For single point solution Ankara $(5 \mathrm{~km})$, Kirikkale $(60 \mathrm{~km})$, Yozgat $(170 \mathrm{~km})$ and Sivas $(360 \mathrm{~km})$ base stations were used as a master station. As it was understood from the result of the solutions that except Sivas and Ankara solution, The ideal situation accuracy were approximately met.

Although the Ankara base GPS station is very close to flight area, it could not supply the expected accuracy. When the base data was investigated, it was seen that PDOP and VDOP of the data was very poor.

It was understood from Sivas base station solution that if master stations were farther than $200 \mathrm{~km}$, it should not be used for GPS $\backslash M U$ process.

First network GPS solution was called Network 1. In this solution, Hendek, Vezirkopru, Kurucaşile and Nevşehir base stations were used and distance from stations to center of the flight area were approximately $230 \mathrm{~km}$. In the network_2 solution, Yunak, Bolu, Kastamonu and Yozgat base stations were used and have approximately $150 \mathrm{~km}$ distance. In the network_3 solution, Camlidere, Kirikkale, Kulu, Nallihan and Yunak base stations were used and the distances from the base stations to flight area are approximately $80 \mathrm{~km}$. Finally network_4 solutions were used in Camlidere, Kirikkale, Kulu, Nallihan, Yunak and Ankara base stations and have approximately $80 \mathrm{~km}$ distance. All the network solutions were approximately met expected accuracy ( The ideal situation accuracy). Network 4 has the highest accuracy in $\mathrm{X}$ and $\mathrm{Z}$ directions and network_3 has the highest accuracy in Ydirection. It was expected that Network 4 had the highest accuracy of the solution but Ankara base station had a bad effect because of PDOP, VDOP and HDOP values.

If the highest accuracy solutions are listed, single point solution by using Ankara base station and PPP have the highest accuracies in X-direction. Network_3 has the highest accuracy in Y-direction and network_4 has the highest accuracy of Zdirection. In generally, it should be better choosing network solution rather than single point solution but if the network distance higher than the $150 \mathrm{~km} \mathrm{Z}$ direction error was grown and in this situation it had better choose single point solution.

Network_1, which is approximately $230 \mathrm{~km}$ distance from the base station to the flight area and the farthest network, solution accuracy is worse especially in Z-direction than single point solution by using Yozgat base station. The distance is not only cause for low accuracy but also the master station's VDOP, HDOP and PDOP values. One or more master stations may have a bad effect.

In General, for network GPS solutions, the network should contain the whole flight area and the GPS stations with bad PDOP and VDOP values should be taken out from the network

\section{CONCLUSIONS}

The acquaintance of direct georeferencing and digital photogrammetry dates back almost ten years ago. Concerning this issue, many studies have been done and still in progress. When these studies are examined about the direct georeferencing, the horizontal accuracies $0,10-0,20 \mathrm{~m}$ and vertical accuracy $0,30 \mathrm{~m}$ was met. These accuracies are affected by the system's mistakes. Except from this, photo scale, flight attitude, baseline of flight plan and location, distinction and configurations of master GNSS station affect this accuracy. Generally, network solutions are chosen for GNSS solutions. The network which is installed with master GNSS station has to cover flight area completely and the GNSS stations which are far maximum $80 \mathrm{~km}$ away from the flight area should be chosen. But in some cases, installing network construction or finding GNSS station which is far away from as required is hardly possible. Especially, network construction can not be installed for border flight or flight on the coasts. In this case, single point solution is chosen. In this study, single point which is different distinction from test area, networks constructions which become different distinctions and configurations, and PPP solutions are examined and its effect for direct georeferencing is researched. The results obtained are so close each other and The horizontal accuracies $\pm 0,20-0,30 \mathrm{~m}$ and vertical accuracy $\pm 0,40$ was met. Only ANKR which is bad data GNSS and SIVS solutions which are far away from 360 $\mathrm{km}$ from flight area can not reach this precision. Generally, network construction solutions are more reliable than other solutions. But instead of solution with the GNSS stations which are installed with the distinction of $150 \mathrm{~km}$ or closer to the flight area, using single point stations which are closer is more appropriate. Instead of using master GNSS station which are far away from working place more than $200 \mathrm{~km}$, using of PPP solution is more appropriate. It is observed that being obtained the measurement from radius of network which is used for network solutions are more than $80 \mathrm{~km}$ is the same with being obtained measurement of solution PPP (Kayı, 2013). 


\section{REFERENCES}

Cramer, M., 2003, Integrated GPS \inertial and digital aerial triangulation - recent test results, Photogrametric Week, Stuttgart 2003.

Cramer, M., Stallmann, D., 2002, System calibration for direct georeferencing, IAPRS, Vol. XXXIV, Part 3A, pp 79-84.

Grejner-Brezezinsk, D.A., 2000, Direct orientation of airborne imagery with GPS \IMU system: performance analysis, navigation,46(4): 261-270.

Grewal, M., Weill, L. ve Andrews, A., (2001). Global positioning systems, inertial navigation and integration,, 103209.2001.

Ip, A.W.L., 2005, Analysis of integrated sensor orientation for aerial mapping, department of geomatics engineering, The University of Calgary, Alberta, Canada.

Jacobsen, K., 2000: Potential and limitation of direct sensor orientation, IAPRS, Vol. XXXIII, Amsterdam 2000.

Jacobsen, K.,(2006). Direct sensor orientation - Pros and Cons, 2004, XXth ISPRS,İstanbul.

Kay1, A., 2013, The effect of single point, network and PPP GNSS data processes on the direct sensor orientation accuracy, Master Degree Thesis, Aksaray University, Aksaray (In Turkish).

Kirac1, A.Ç., İşcan, L., Eker, O., Akabalı, O.A., 2008, Aerial photogrametry and direct georeferencing with GPS\IMU data test results, Tufuab (In Turkish).

Mostafa, M.R. ve Huttun, J., 2001, Direct positioning and orientation system - how do they work? what is the attainable accuracy? proceeding, ASPRS Annual Meeting,St Louis,Mo,USA,April 22-27.

Skaloud, J., 2007, Reliability of direct georeferencing - beyond the achilles' heel of modern airborne mapping, Photogrammetry Week,2007.

Yast1kl1, N., 2003. Direct georeferencing of aerial photography with using GPS/IMU data and integrated block triangulation , Ph. D. , Yıldız Teknik University, Y1ldız, İstanbul.

\section{ACKNOWLEDGEMENTS}

The authors would like to thank the General Command of Mapping of TURKEY. The manuscript solely reflects the personal views of the author and does not necessarily represent the views, positions, strategies or opinions of Turkish Armed Forces. 